\title{
Composition and evaluation of a novel web-based decision support system for grape black rot control
}

\author{
Daniel Molitor • Barbara Augenstein - Laura Mugnai • Pietro Antonello Rinaldi • \\ Jorge Sofia • Bryan Hed • Pierre-Henri Dubuis • Mauro Jermini • Erhard Kührer • \\ Gottfried Bleyer • Lucien Hoffmann • Marco Beyer
}

Accepted: 14 December 2015 /Published online: 23 December 2015

(C) Koninklijke Nederlandse Planteziektenkundige Vereniging 2015

\begin{abstract}
Black rot on grapevine is a fungal disease caused by Phyllosticta ampelicida (syn. Guignardia bidwellii) affecting grape leaves as well as clusters. A novel black rot decision support system termed VitiMeteo Black rot was assembled based on
\end{abstract}

D. Molitor $(\bowtie) \cdot$ L. Hoffmann $\cdot$ M. Beyer

Environmental Research and Innovation (ERIN) Department, LIST - Luxembourg Institute of Science and Technology, 4422 Belvaux, Luxembourg

e-mail: daniel.molitor@list.lu

L. Hoffmann

e-mail: lucien.hoffmann@list.lu

M. Beyer

e-mail: marco.beyer@list.lu

\section{Molitor}

Department of Crop Sciences, Division of Viticulture and Pomology, University of Natural Resources and Life Sciences, 3430 Tulln, Austria

B. Augenstein

Geosens Ingenieurpartnerschaft, 79285 Ebringen, Germany

e-mail: b.augenstein@geosens.de

L. Mugnai · P. A. Rinaldi

Dipartimento di Scienze delle Produzioni Agroalimentari e dell'Ambiente, University of Florence, 50144 Florence, Italy

L. Mugnai

e-mail: laura.mugnai@unifi.it

P. A. Rinaldi

e-mail: pedrorinaldi@yahoo.co.uk existing sub-models and incorporated into the established VitiMeteo forecast and decision support platform. Based on local weather data and a 5-day weather forecast, VitiMeteo Black rot simulates the relative susceptibility of grape clusters, the occurrence

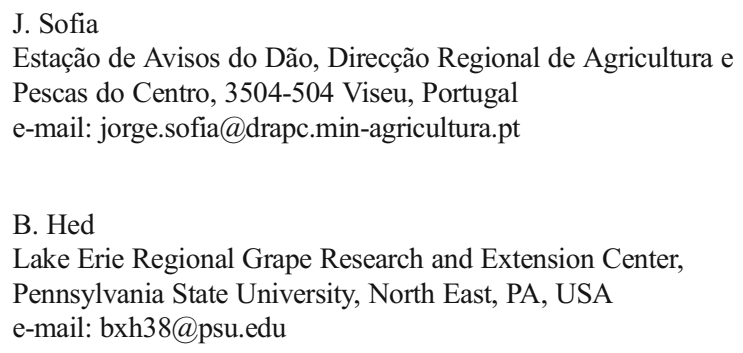

\section{P.-H. Dubuis}

Agroscope, Station de Recherche Changins, 1260 Nyon, Switzerland e-mail: pierre-henri.dubuis@acw.admin.ch

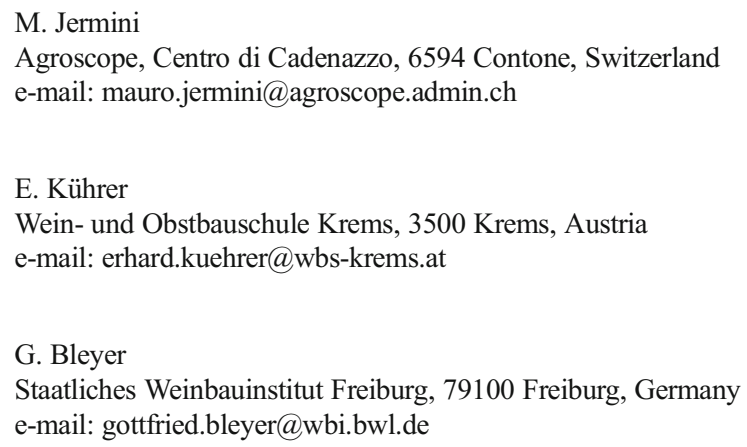


and severity of infection events as well as the duration of incubation periods. Data sets obtained in extended international (14 case studies; eight monitoring locations; 11 cultivars; seven countries in Europe and North America) field monitoring campaigns in 2012 and 2013 were used to evaluate the model predictions of newly expressed symptoms on leaves. In the case of the Vitis vinifera cultivars, on average 26.3 disease assessments took place per season. On average, 9.9 predictions were classified as true positive, 8.0 as true negative, 5.2 as false positive and 3.2 as false negative. Model precision, sensitivity and accuracy were on average 64, 77 and $67 \%$. Potential reasons for false positive and false negative predictions are discussed. VitiMeteo Black rot is freely available for several locations in Germany, Luxembourg and Austria on the internet via the VitiMeteo platform and might be expanded to other regions in the future.

Keywords Decision support system - Grape black rot . Guignardia bidwellii $\cdot$ Model evaluation $\cdot$ Phyllosticta ampelicida $\cdot$ VitiMeteo

\section{Introduction}

Black rot is a fungal disease on grapevine caused by Phyllosticta ampelicida (Engelm.) Aa (syn. Guignardia bidwellii (Ellis) Viala et Ravaz). The disease is native to North America and was first reported in Europe in 1885 (Viala and Ravaz 1886). Since the beginning of the $21 \mathrm{st}$ century, an increased occurrence of the disease has been reported from several grape growing regions in Germany, Switzerland, Austria, Luxembourg and Romania (Rinaldi et al. 2013a). Recently, black rot also has appeared more frequently in the warmer Mediterranean European countries such as Italy and Portugal (Rinaldi et al. 2013b). Severe epidemics cause yield losses of up to $100 \%$ (Rinaldi et al. 2013b) making black rot one of the economically most important fungal diseases of grapevine in the regions concerned. Successful black rot control strategies integrate sanitary measures, cultural techniques, the use of cultivars with lower susceptibility as well as direct chemical control measures (Hoffman et al. 2004; Molitor and Beyer 2014). Black rot infections are possible by both, conidia and ascospores. Conidia liberated in vast quantities (Harms et al. 2005) are responsible for the rapid spread of the disease in the field (Ferrin and Ramsdell
1978) and are hence considered as the major source of black rot infections during summer (Loskill et al. 2009; Molitor and Beyer 2014). In general, black rot infections on leaves (Spotts 1977), grape berries (Molitor 2009) and shoots (Northover 2008) are possible if temperature dependent wetness durations are exceeded. Based on wetness period duration and temperature, a black rot infection index for grape leaves was derived from growth chamber trials to allow models to differentiate between the effects of no infection, light infection, moderate infection or severe infection (Molitor 2009). When wetness periods are disrupted by dry intervals, the resulting disease severity is reduced, even though intermediate dryness periods do not completely inhibit infections (Spotts 1980; Molitor 2009).

To simulate grape black rot infection events, Ellis et al. (1986) developed a microprocessor program based on the specific wetness requirements identified by Spotts (1977). More recently, Smith and Sutherland (2010) established the "Black Rot Advisor" that incorporates a 3-day weather forecast and gives recommendations for fungicide applications. However, previously established models did not consider the severity of infection events and variations in host susceptibility over time (as identified by Hoffman et al. 2002; Molitor and Berkelmann-Löhnertz 2011). Furthermore, the influence of temperature and phenological development on the duration of the incubation period as described by Spotts (1980), Hoffman et al. (2002) and Molitor et al. (2012) remained unconsidered.

In recent years, several forecast and decision support systems were developed for other major fungal diseases in viticulture. Exemplarily, the models set up by Rossi et al. (2008) and Caffi et al. (2011) as well as the "VitiMeteo" models for downy and powdery mildew (Bleyer et al. 2011) should be mentioned. However, practical black rot management strategies still mainly focus on routine applications of efficient fungicides. A precise black rot decision support system has been lacking compiling: (i) the present knowledge on the biology of the pathogen and epidemiology of the disease, as well as (ii) aiming at a more targeted timing of fungicide treatments.

Hence, the aims of the present study were: (i) to assemble a model system simulating the key steps in the biology of the pathogen and in the epidemiology of the disease, (ii) to evaluate the model output for grape leaves under different climatic conditions and for different grape cultivars, and (iii) to incorporate the model 
system in the established forecast and decision support platform VitiMeteo.

\section{Material and methods}

Model descriptions

VitiMeteo Black rot is based on algorithms simulating the epidemiologically relevant aspects of the development of plant and pathogen (Table 1).

The input variables for running those models are: (i) the hourly or daily data of temperature and hourly data of leaf wetness recorded by a nearby weather station or simulated by a 5-day weather forecast (Weather Research and Forecasting Model (WRF), provided by Meteoblue AG, Basel, Switzerland), and (ii) the dates of the major phenological growth stages budburst $(\mathrm{BBCH}$ 11 according to Lorenz et al. (1995)) and end of flowering (BBCH 68).

In VitiMeteo Black rot the development of the primary shoot leaf area is modelled according to Schultz (1992). Briefly, the model by Schultz (1992) simulates the emergence of new primary shoot leaves as well as the expansion of every single primary shoot leaf based on daily average temperatures (lower threshold temperature: $10^{\circ} \mathrm{C}$ ) and computes the total primary shoot leaf area per shoot; secondary (lateral) shoot leaves are not considered. Model validation of Schultz (1992) showed that the model closely describes the development of primary shoot leaves as well as of the primary shoot leaf area under cool climate conditions.

The simulation starts with the day of grape budburst. Leaves that have already reached their final size and those that are still expanding are modelled separately. Total primary shoot leaf area as well as the leaf area of primary shoot leaves presently still expanding are calculated.

\section{Susceptibility of grape organs}

Only young, still-expanding leaves are susceptible to black rot infections (Kuo and Hoch 1996). Hence, the cumulative primary shoot leaf area of leaves that are still expanding is considered as the "susceptible leaf area". Since grape leaves are susceptible starting with budburst (Molitor 2009), the period of leaf susceptibility starts with the date of budburst.
The susceptibility of grape clusters to conidial infections depends on their phenological development and can be simulated according to Molitor (2009) (Equation 1; Table 1).

The period of cluster susceptibility ends around $450 \mathrm{CDD}_{>10^{\circ} \mathrm{C}}$ (Molitor and Berkelmann-Löhnertz 2011).

\section{Infection index}

Based on disease severity levels reached in growth chamber trials on leaves of potted vines following inoculation (Molitor 2009), the infection index (II) as a function of the temperature and the length of the wetness period can be calculated according to Equation 2 (Table 1).

The accumulation of the infection index begins in the hour when a wetness period starts and stops in the hour when it ends. The end of a calendar day does not terminate the accumulation. After reaching an infection index value of 85 cumulative degree hours, the requirements for conidial infections are fulfilled (Molitor 2009). Once the infection index surpasses this value, an infection event (as the starting point of an incubation period) is fixed and displayed as a violet triangle in the model output. For reason of clarity, the number of infection events displayed and incubation curves started is limited to 1 per day.

The severity of individual conidia-based infection events is also expressed in terms of the infection index (Molitor 2009) (Equation 2). Based on the maximum value of the infection index per calendar day, the maximum infection severity on this day was classified into the four categories (Table 1). Categories were defined according to disease severities assessed on leaves of potted vines depending on the length of exposure to leaf wetness at different temperatures in growth chamber trials (Molitor 2009).

If no leaf wetness (hourly average values) is indicated by the leaf wetness sensor, this period is considered as a dry period. When consecutive wetness periods are disrupted by drought periods, the severity of the resulting infection events (in terms of final disease severity) is reduced (Spotts 1980; Molitor 2009). Thus, in the model the infection index values are accumulated as long as wetness conditions are recorded. But once a dry period starts, the value of the infection index at this point is reduced by $30 \%$ for each hour that 


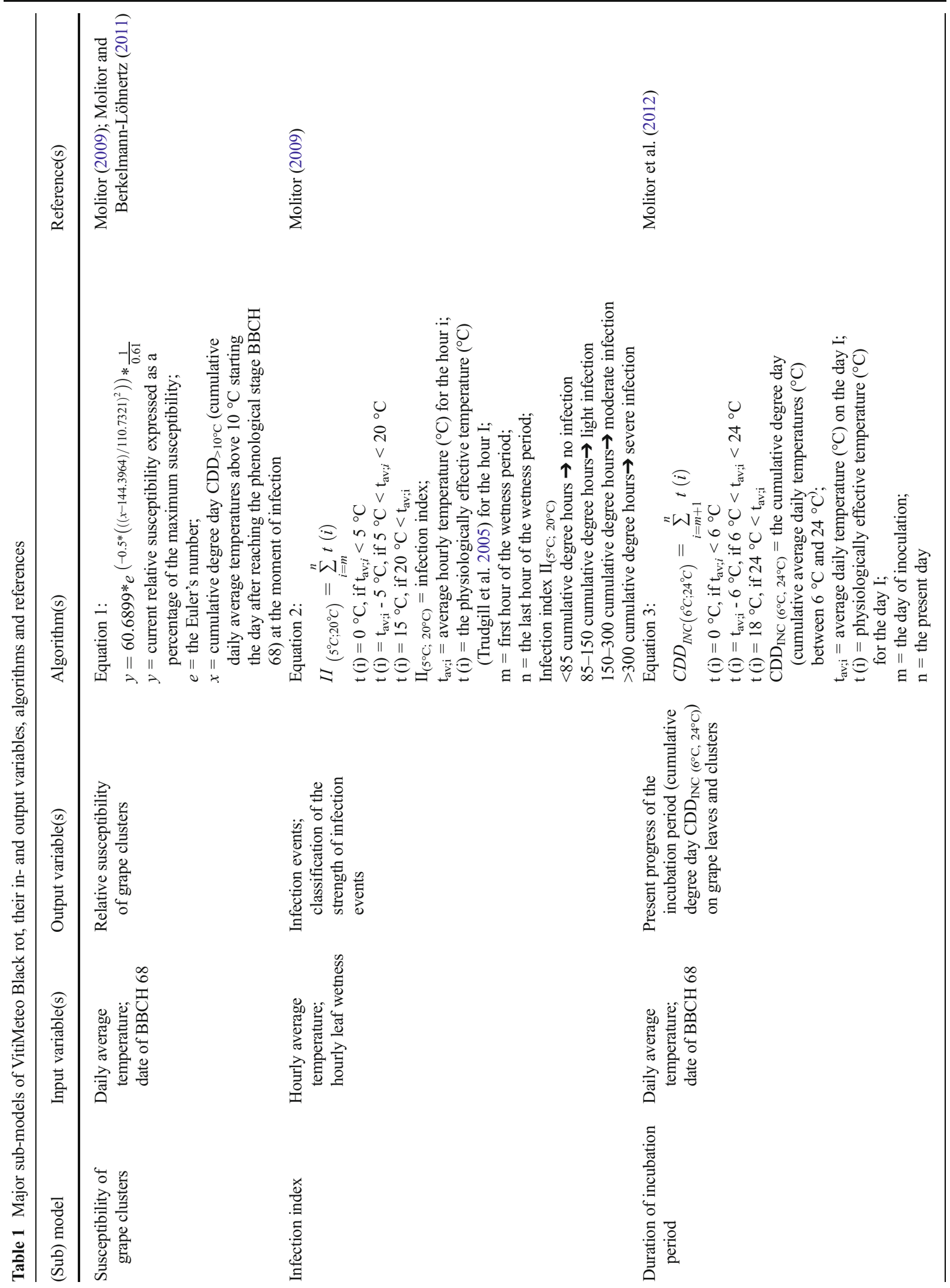




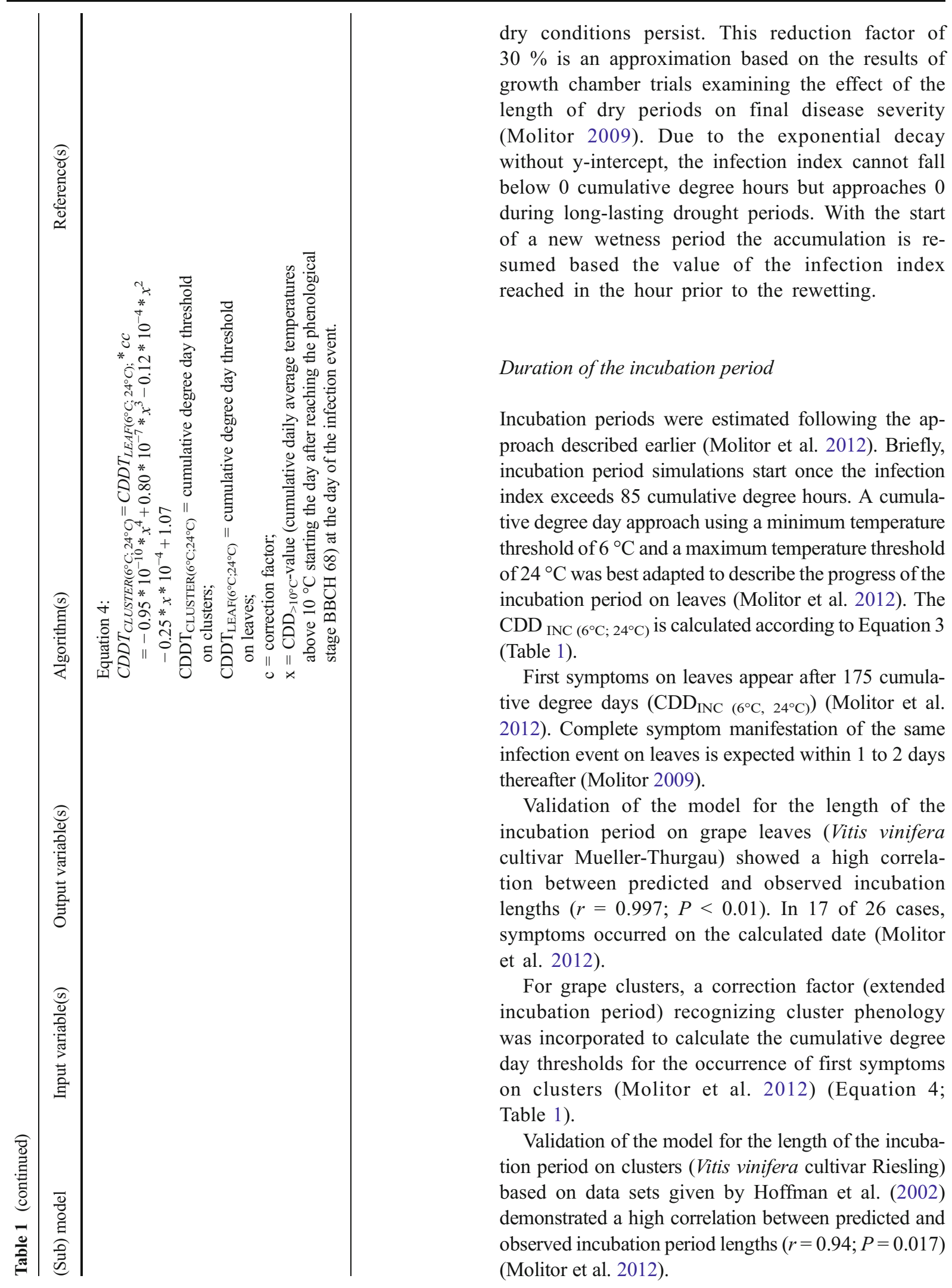


Model evaluation for grape leaves

\section{Field monitoring}

In order to evaluate the model performance under different climatic conditions and for different grape varieties, black rot monitoring campaigns on grape leaves were conducted at eight locations in six European countries (Changins and Cugnasco/Switzerland, Freiburg/ Germany, Florence/Italy, Krems-Landersdorf/Austria, Nelas/Portugal, Remich/Luxembourg) as well as in the USA (North East/Pennsylvania) in the years 2012 and 2013.

The locations, their geographic coordinates, cultivars monitored as well as years of monitoring are summarized in Table 2. The total number of case studies was 14.

Gutedel, Sangiovese, Grüner Veltliner, Jaen, Müller-Thurgau and Pinot noir are Vitis vinifera cultivars, while Concord is a Vitis labrusca cultivar and Divico, Prior, Solaris and Souvigner gris are interspecific hybrids.

In the monitoring fields, five to ten plants remained either untreated or were treated with fungicides without indicated or known black rot activity. To ensure adequate inoculum potential at the beginning of each season (independent of the natural inoculum), grape clusters infected in the previous season ("fruit mummies") were wrapped in meshes and fixed in the monitoring plots on the upper wire of the vineyard trellis in a horizontal distance of approximately $20 \mathrm{~cm}$ relative to each other.

Mummies were harvested in the respective regions in vineyards severely infected by black rot in the previous season shortly before fixing them in the experimental fields.

At each location, the appearance of black rot symptoms on the primary shoot leaves was assessed by visual inspection two to three times per week. The dates of initial and final assessments as well as the total number of assessments are summarized for each case study in Table 3.

Upon appearance of the first symptoms, five symptomatic shoots were selected and followed thereafter over the entire season. At each assessment date, the number of new lesions on each primary shoot leaf was noted (with the exception of North East, where exclusively the appearance of new lesions on previously symptomless leaves was recorded).

The period between two assessment dates is subsequently referred to as an "assessment interval".

Hourly data of air temperature and leaf wetness were recorded in direct proximity ( $<=1 \mathrm{~km}$ distance) to the fields of observation except for the location Nelas/ Portugal, where weather data originated from the weather station Viseu located approximately $20 \mathrm{~km}$ NorthWest of Nelas.

Table 2 Locations, coordinates, cultivars and years of black rot monitoring for model evaluation

\begin{tabular}{llll}
\hline Location & Coordinates & Cultivar & Years \\
\hline Changins (Switzerland) & $46.40^{\circ} \mathrm{N}, 6.23^{\circ} \mathrm{E}$ & Gutedel (syn. Chasselas) & $1(2012)$ \\
Cugnasco (Switzerland) & $46.17^{\circ} \mathrm{N}, 8.93^{\circ} \mathrm{E}$ & Divico & $1(2012)$ \\
& & Prior & $1(2013)$ \\
& & Solaris & $1(2013)$ \\
& & Souvigner gris & $1(2013)$ \\
Florence (Italy) & $43.76^{\circ} \mathrm{N}, 11.24^{\circ} \mathrm{E}$ & Sangiovese & $2(2012,2013)$ \\
Freiburg (Germany) & $47.98^{\circ} \mathrm{N}, 7.83^{\circ} \mathrm{E}$ & Gutedel (syn. Chasselas) & $2(2012,2013)$ \\
Krems-Landersdorf (Austria) & $48.42^{\circ} \mathrm{N}, 15.62^{\circ} \mathrm{E}$ & Grüner Veltliner & $1(2013)$ \\
Nelas (Portugal) & $40.52^{\circ} \mathrm{N}, 7.86^{\circ} \mathrm{W}$ & Jaen & $1(2013)$ \\
North East (USA) & $42.19^{\circ} \mathrm{N}, 79.86^{\circ} \mathrm{W}$ & Concord & $1(2013)$ \\
Remich (Luxembourg) & $49.54^{\circ} \mathrm{N}, 6.35^{\circ} \mathrm{E}$ & Müller-Thurgau (syn. Rivaner) & $1(2012)$ \\
& & Pinot noir & $1(2013)$ \\
Total & & & 14 \\
\hline
\end{tabular}




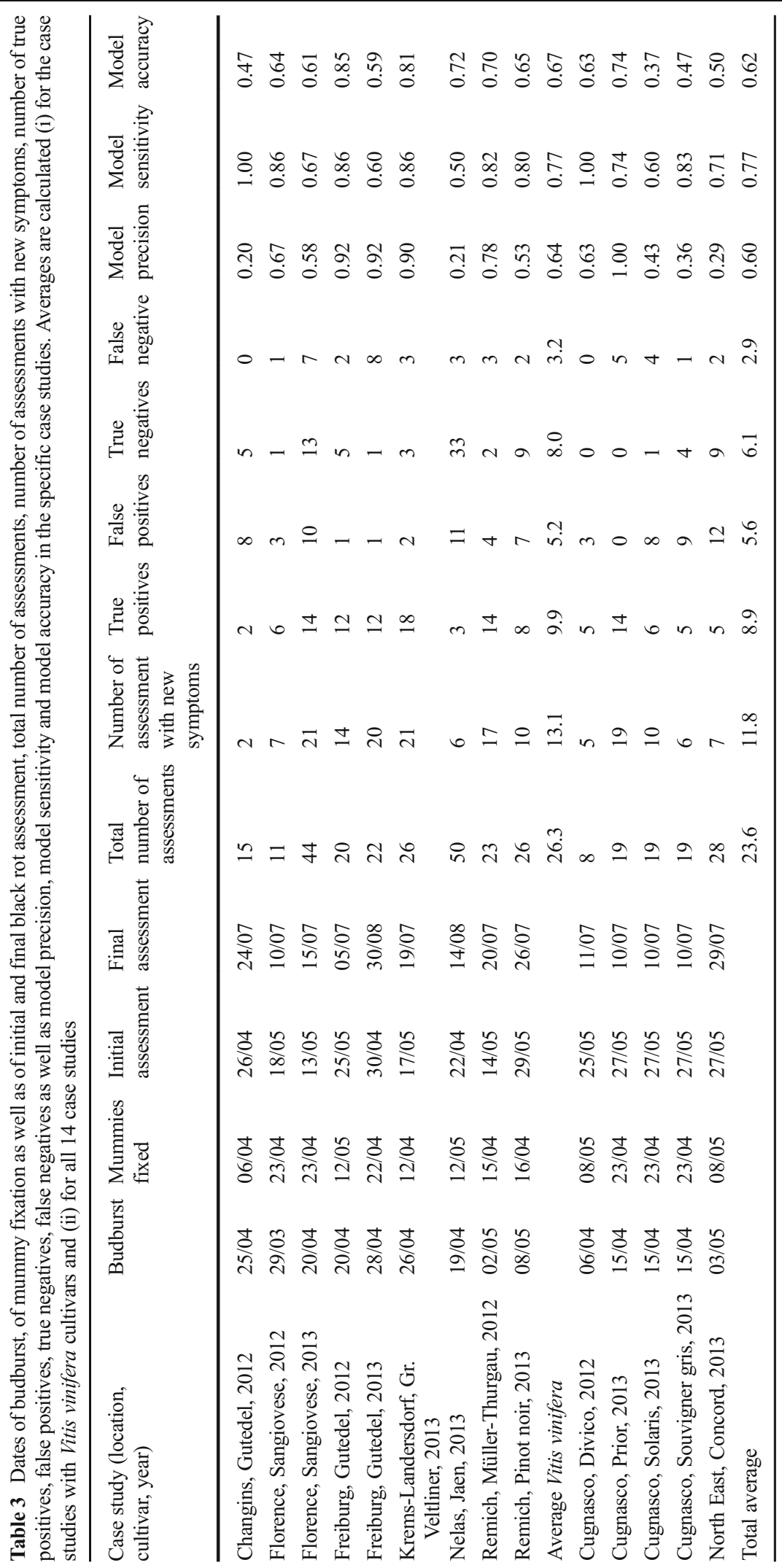




\section{Data analyses}

For each simulated infection event (infection index $>=85$ cumulative degree hours), the predicted dates of new symptom appearance on leaves (predicted dates of infection events + simulated duration of the incubation period) were calculated.

Provided that new symptoms were observed at an assessment date and if the predicted date of the end of any incubation period was located within the assessment interval, the prediction was classified as true positive.

If no new symptoms were observed at an assessment and no predicted incubation period ended within the assessment interval, the prediction was classified as true negative.

If no new symptoms were observed at an assessment date but at least one predicted incubation period ended within the assessment interval, the prediction was classified as false positive ("false alarm", type I error).
If new symptoms were observed in an assessment interval but no predicted incubation period ended within the assessment interval, the prediction was classified as false negative (type II error) (Fig. 1).

For each case study, the quality of the model prediction was quantified in terms of the model precision (positive predictive value), the model sensitivity (true positive rate) and the model accuracy as defined by Eqs. 5 to 7.

$$
\text { Model precision }=\frac{\text { nr of true positives }}{\text { nr of true positives }+ \text { nr of false positives }}
$$

Model sensitivity $=\frac{\mathrm{nr} \text { of true positives }}{\text { nr of true positives }+ \text { nr of false negatives }}$

Model accuracy $=\frac{\mathrm{nr} \text { of true positives }+\mathrm{nr} \text { of true negatives }}{\mathrm{nr} \text { of true positives }+\mathrm{nr} \text { of false positives }+\mathrm{nr} \text { of false negatives }+\mathrm{nr} \text { of true negatives }}$

\section{Results}

Model outputs

Model output data are presented as both, a user as well as an expert version. The user version is directly accessible by grape growers on the internet via the VitiMeteo platform. The expert version is dedicated to data analyses as well as evaluation and adaptation of model parameter settings and is not publicly available.

i. Web-based user version

In the user version, the model output is presented by means of two overview graphs (starting 14 days in the past and ending 5 days in the future (based on weather forecast data)) following the established structure of the VitiMeteo platform (Bleyer et al. 2008).

The overview graph A (Fig. 1a) presents the time courses of:

- the daily average, minimum and maximum temperatures; the daily precipitation sums and the daily average values of the relative humidity

- the hourly leaf wetness. Periods of leaf wetness are indicated in blue.

- the daily infection severity (daily maximum value of the infection index expressed in four categories presented as coloured rectangles (green: $\mathrm{II}_{\left(5^{\circ} \mathrm{C}, 20^{\circ} \mathrm{C}\right)}<85$ cumulative degree hours $\rightarrow$ no infection; yellow: $\mathrm{II}_{\left(5^{\circ}\right.}$ $\left.\mathrm{C}, 20^{\circ} \mathrm{C}\right)$ between 85 and 150 cumulative degree hours $\rightarrow$ light infection; orange: II $\left(5^{\circ} \mathrm{C}, 20^{\circ} \mathrm{C}\right)$ between 150 and 300 cumulative degree hours $\rightarrow$ moderate infection, red: II $\left(5^{\circ} \mathrm{C}, 20^{\circ} \mathrm{C}\right)>300$ cumulative degree hours $\rightarrow$ severe infection)

- the relative susceptibility of the berries (in \% of their maximum susceptibility)

- the number of presently unfolded leaves, the total primary shoot leaf area per shoot (light and dark green) as well as the primary shoot leaf area per shoot of leaves presently still expanding (susceptible leaf area). 
In overview graph $\mathrm{B}$, the model outputs as well as the weather data are presented:

- the progression of the incubation period on leaves (green line) and the extended incubation period on berries (red line). The incubation period of the specific organs ends when the end of the incubation line is reached.

- the infection events (violet triangles)

- hourly data of the temperature, the precipitation sums, the relative humidity and the leaf wetness.

Furthermore, model output and weather data are presented as numerical data exportable to common spreadsheet software packages.

In the user version, model parameter settings cannot be modified.

\section{ii. Expert version}

The model output in the expert version consists of a graphical presentation of the two overview graphs as presented for the user version.

Here, in contrast to the user version, all parameter settings (besides meteorological input variables), such as dates of budburst or flowering and biological algorithms, can be adjusted manually by the expert user on either a global scale or specifically for a single location.

Model evaluation

Monitoring periods and the number of assessments are given in Table 3. A graphical example for the model evaluation is given in Fig. 2. Here, violet triangles represent the starting point of the incubation period, green lines represent latent infections during their incubation periods on grape leaves, and red lines the extended incubation periods on grape clusters. The end of the incubation period is reached at the end point of the green line for leaves or the red line for berries, respectively. Light green rectangles show the observed intervals of new symptom appearance (Fig. 2).

In total, 330 assessments took place. In 165 cases model predictions were true positive, in 86 cases true negative, in 79 cases false positive (false alarm), and 41 cases false negative (Table 3 ).

With default model parameter settings (infection index threshold: 85 cumulative degree hours) average (across all 14 case studies used for model evaluation) model precision was $60 \%$ (Table 3 ). Model precisions below $50 \%$ were observed in the case studies Cugnasco, Solaris, 2013; Cugnasco, Souvigner gris, 2013 (interspecific hybrids) North-East, Concord, 2013 (Vitis labrusca), Changins, Gutedel, 2012 and Nelas, Jaen, 2013. On average of all 14 case studies model sensitivity was $77 \%$ with the lowest sensitivity in case of Nelas, Jaen, 2013. Average model accuracy of all 14 case studies was $62 \%$. Model accuracies below $50 \%$ were observed in the case studies Cugnasco, Solaris, 2013; Cugnasco, Souvigner gris, 2013 (interspecific hybrids) and Changins, Gutedel, 2012 (Table 3).

In case of the Vitis vinifera cultivars, on average 26.3 assessments took place per season. On average, predictions were 9.9 time true positive, 8.0 times true negative, 5.2 times false positive and 3.2 false negative. Here, model precision, sensitivity and accuracy were on average 64,77 and $67 \%$ (Tables 3 and 4).

\section{Discussion}

Model performance

Model precision defined by the number of true positive predictions relative to all positive predictions, was on average $60 \%$. False positive predictions seemed to be preferentially coupled with genotypes of reduced sensitivity towards fungal pathogens such as the interspecific crossings Solaris (Merzling $\times$ Gm 6493) and Souvigner gris (Gamaret $\mathrm{x}$ Bronner) evaluated in Cugnasco. This might indicate that the cultivar Merzling, a direct ancestor of the cultivar Solaris as well as of Bronner (mother vine of Divico and Souvigner gris), constitutes a potential source for black rot tolerance. However, the absence of false positive predictions (model precision: 100 \%) in case of the Merzling descendant Prior ((Joannès-Seyve 23-416 $\times$ Pinot noir $) \times$ Bronner $[=$ Merzling $\times \mathrm{Gm}$ 6494]) suggests that not all Merzling descendants express a reduced sensitivity towards black rot.

Also in the case study of the Vitis labrusca cultivar Concord, model precision was relatively low (29\%). This effect could be explained either by the fact that (contrarily to the other case studies) only the appearance of new lesions on leaves previously symptomless was recorded (which explains the higher number of false positives) or by a reduced susceptibility of Concord. In 

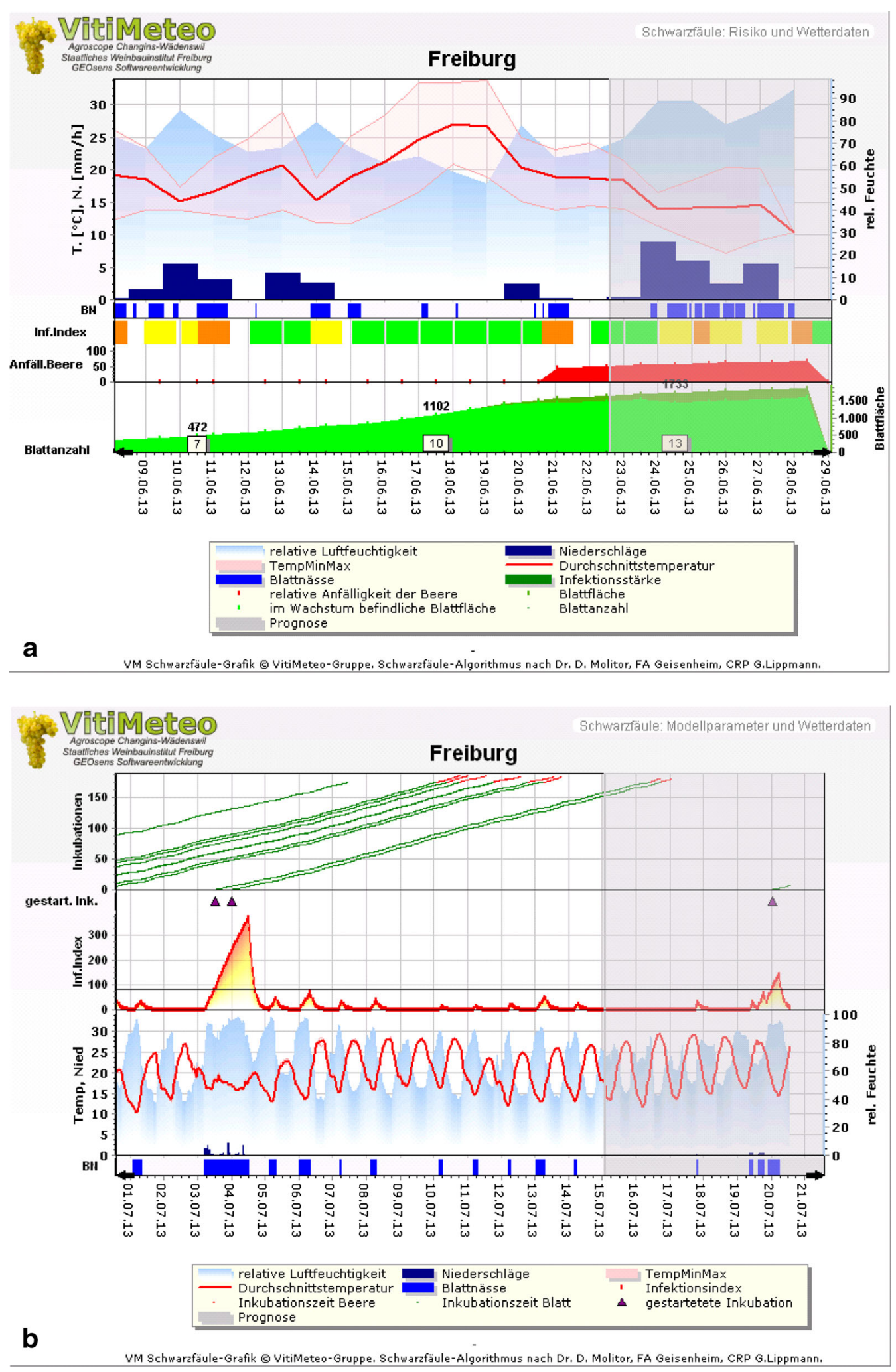
Fig. 1 Examples for the user version of the overview graphs a and b. $\mathrm{T}, \mathrm{Temp}=$ temperature; Durchschnittstemperatur = hourly average temperature; TempMinMax $=$ daily minimum and maximum temperature; N, Nied, Niederschläge = precipitation; relative Luftfeuchtigkeit, rel. Feuchte = relative humidity; Inf. Index, Infektionsindex = infection index; Anfäll. Beere, relative Anfälligkeit der Beeren = relative susceptibility of grape clusters; Blattanzahl $=$ number of primary shoot leaves; Blattfläche = primary shoot leaf area; Blattnässe = leaf wetness; im Wachstum befindliche Blattfläche = cumulative primary shoot leaf area of leaves that are still expanding (susceptible leaf area); Prognose = prognosis; Inkubationen = running incubation periods; gestart. Ink., gestartete Inkubation $=$ starting points of incubation periods; Inkubationszeit Beere $=$ extended incubation period on grape clusters; Inkubationszeit Blatt $=$ incubation period on grape leaves

fact, Hoffman et al. (2002) showed that the berries of cv. Concord remain susceptible for a shorter period of time compared to the berries of $V$. vinifera cultivars and the same might be true for young, expanding cv. Concord leaves.

The rather poor model precision and sensitivity for Nelas might be related to the fact that the only weather data available were recorded approximately $20 \mathrm{~km}$ distant from the monitoring field.
Model sensitivity is inversely proportional to the number of false negative predictions, i.e., the observation of new symptoms without an accompanying infection event being predicted previously. For practical control strategies, false negative predictions are more harmful than false positives since the failure to protect against infection events might lead to severe black rot attack and crop losses.

With exception of Nelas, Jaen, the percentage of false negative predictions was generally relatively low in the present case studies (model sensitivity $>=0.60$ ) indicating that false negative predictions (symptoms observed without accompanying predicted infection events) were relatively rare cases. This is particularly noteworthy as symptoms appearing 1 day before or after the predicted end of the incubation period were classified as false negative predictions. In consequence, such false negative predictions might be explained e.g. by specific traits of specific cultivars leading to a deviating duration of the incubation period or an extended period of symptom appearance.

In general, it has to be kept in mind, that the present model system is based on different sub-models. Due to the coupling of those models potential deviations caused

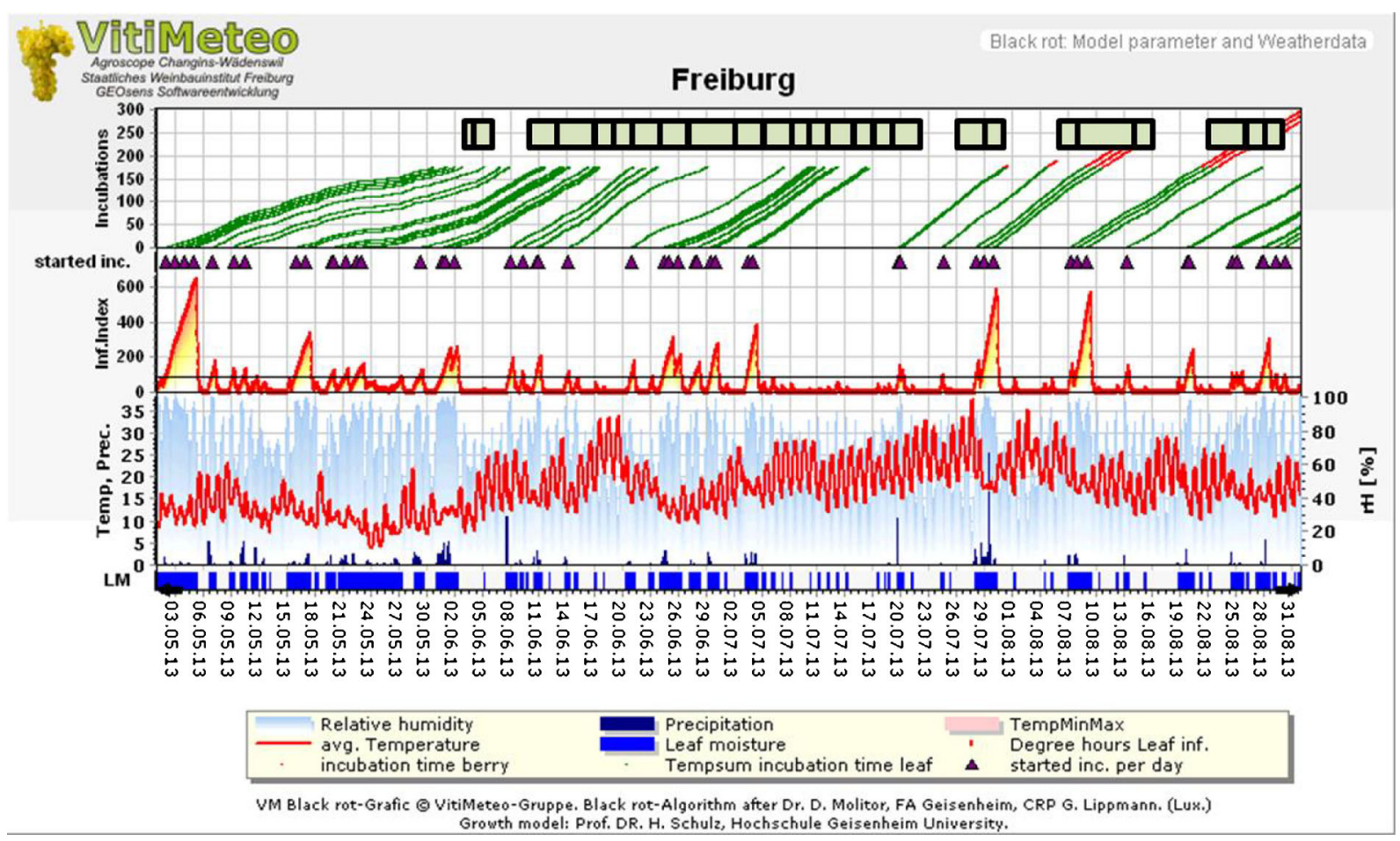

Fig. 2 Example for the expert version of overview graph B illustrating the model evaluation. Here, light green rectangles show intervals of new symptom appearance 
Table 4 Evaluation matrix for model evaluation on Vitis vinifera cultivars. Average (10 case studies) of true positive, true negative, false positive and false negative predictions per case study are shown

\begin{tabular}{llll}
\hline & & \multicolumn{2}{l}{ New symptoms observed at assessment } \\
\cline { 3 - 4 } & & Yes & No \\
\hline $\begin{array}{l}\text { Predicted end of an incubation period } \\
\text { in assessment period }\end{array}$ & Yes & 13.1 (true positive) & $\begin{array}{l}5.2 \text { (false positive) } \\
\text { No }\end{array}$ \\
\hline
\end{tabular}

by the model algorithms (model-wise errors) or the meteorological input data might be accumulated or multiplied. This is especially the case if meteorological input data are systematically biased (e.g., due to distance between the site of observation and meteorological station, biases causes by meteorological instruments).

Targeted implementation of the decision support system in practical black rot control strategies

Lately, an additional black rot model has been presented as part of a web-based decision support system for integrated viticulture (Rossi et al. 2014). In contrast to the present approach, this model focuses on the simulation of ascospore and conidia formation, maturation and dispersal. Since studies of Loskill et al. (2009) demonstrated that spores (conidia or ascospores) are produced throughout the growing season in the overwintering mummies, VitiMeteo Black rot assumes sufficient inoculum to be present throughout the season (in regions or vineyards with black rot symptoms in the previous or the present year). Since conidia are responsible for the rapid spread of the disease in the field (Ferrin and Ramsdell 1978), they are considered as major source of infections during summer (Molitor and Beyer 2014).

In general, input models of VitiMeteo Black rot are considering exclusively conidial infections. Differences in the infection process or the following incubation period in case of ascospores would merit further investigations. Model evaluation in fact demonstrated the adequacy of the purely conidia based input models in case of overwintered fruit mummies as inoculum source, which release ascospores as well as conidia (Loskill et al. 2009).

For the timing of control measures, the recognition of black rot infection events and of their severity is of particular importance. Due to the long incubation period (Molitor et al. 2012) the allocation of new black rot symptoms to its corresponding infection events is often difficult in practical viticulture. Consequently, in VitiMeteo Black rot the incubation period lines plotted in overview graph B allow an exact allocation of symptoms to the causal infection event. Furthermore, the included 5-day-weather-forecast permits the prediction of the appearance of new symptoms in the future (provided that no control measures have taken place).

Black rot lesions on leaves reduce assimilation and form the inoculum for further infections during the season while most severe damage is caused by cluster infections. From an economic point of view, almost no black rot damage on the clusters can be tolerated (Molitor and Beyer 2014).

Following the principles of Integrated Pest Management (IPM), direct control measures on grape clusters should take into account the host plants' actual level of susceptibility (Ficke et al. 2002). In the present model system, the relative susceptibility of grape clusters is not influencing the severity of infection events but is displayed in the overview graph A as percentage of maximum susceptibility for every day of the season. This information is offered to support practical control decisions concerning the choice of active ingredients to be applied. QoI (quinone outside inhibitors) or DMI (demethylation inhibitors) type fungicides are of high efficacy in black rot control on grape clusters (Molitor et al. 2011). Hence, both QoIs as well as DMIs can be recommended in practical viticulture, especially in the period of highest berry susceptibility indicated by the model.

The graphical presentation of the infection index as well as the displayed categories of infection event severities specifies the infection status in the past as well as for 5 days in the future. Consequently, protective fungicides can be applied closely prior to expected infection events. Curative applications might be conducted as a reaction to indicated strong infections. If no infections took place in the near past and no infections events are indicated for the future, protective applications might be postponed when control of the other grape diseases allows for this.

The potential to reduce the number of fungicide applications seems to be most pronounced in regions 
where the number of infections events is limited. This is especially the case in drier viticultural regions such as the Mediterranean area. Generally, it has to be kept in mind, that the precision of the VitiMeteo Black rot model output into the future is clearly determined by the precision of the weather forecast.

In the expert version of VitiMeteo Black rot all parameter settings (besides meteorological input parameters) can be adjusted manually. Adjustments are possible in case of the dates of budburst or flowering as well as in case of biological algorithms. Adjusting biological algorithms might be appropriate in case improved knowledge on the biology of the pathogen or the epidemiology of the disease becomes available. At present, modifications on the biological algorithms are generally not recommended since they might significantly distort the model outputs.

In the present model status, the key phenological growth stages of grapevine need to be entered manually into the system. In a next step of model evolution the dates of budburst will be simulated directly implementing a budburst model such as the model of Caffarra and Eccel (2009), Nendel (2010) or Molitor et al. (2014a) in combination with phenological models to simulate the date of $\mathrm{BBCH} 68$ such as the highresolution grape phenology model of Molitor et al. (2014b).

Acknowledgments The authors wish to thank S. Fischer and R. Mannes (Institut Viti-vinicole (IVV), Remich, Luxembourg) for providing experimental vineyards, M. Skaventzou (University of Florence, Italy), N. Baron, M. Pallez, L. Giustarini (LIST, Belvaux, Luxembourg), C. Rieger, P. Erhardt and M. Grundler (Staatliches Weinbauinstitut Freiburg, Germany), L. Torriani (Agroscope Cadenazzo, Switzerland), S. Garidel (IVV Remich, Luxembourg) for technical assistance in the field monitoring as well as in GIS, B. Berkelmann-Löhnertz (Geisenheim University, Germany), G.K. Hill (DLR Rheinhessen-Nahe-Hunsrück, Oppenheim, Germany), O. Viret (Agroscope Changins, Switzerland), H.H. Kassemeyer (Staatliches Weinbauinstitut Freiburg, Germany) and R. Krause (Geosens Ingenieurpartnerschaft, Ebringen, Germany) for supporting the development and implementation of the model as well as the Institut Viti-viticole (Remich, Luxembourg) for financial support in the framework of the research project „ProVino - Pesticide reduction in viticulture“.

\section{References}

Bleyer, G., Kassemeyer, H.-H., Krause, R., Viret, O., \& Siegfried, W. (2008). „VitiMeteo Plasmopara“ - Prognosemodell zur
Bekämpfung von Plasmopara viticola (Rebenperonospora) im Weinbau. Gesunde Pflanze, 60, 91-100.

Bleyer, G., Kassmeyer, H. H., Breuer, M., Krause, R., Viret, O., Dubuis, P.-H., Fabre, A., Bloesch, B., Siegfried, W., Naef, A., \& Huber, M. (2011). "VitiMeteo" - a future-oriented forecasting system for viticulture. IOBC/wprs Bulletin, 67, 6977.

Caffarra, A., \& Eccel, E. (2009). Increasing the robustness of phenological models for Vitis vinifera cv. Chardonnay. International Journal of Biometeorology, 54(3), 255-267.

Caffi, T., Rossi, V., Legler, S. E., \& Bugiani, R. (2011). A mechanistic model simulating ascosporic infections by Erysiphe necator, the powdery mildew fungus of grapevine. Plant Pathology, 60, 522-531.

Ellis, M. A., Madden, L. V., \& Wilson, L. L. (1986). Electronic grape black rot predictor for scheduling fungicides with curative activity. Plant Disease, 70(10), 938-940.

Ferrin, D. M., \& Ramsdell, D. C. (1978). Influence of conidia dispersal and environment on infection of grape by Guignardia bidwellii. Phytopathology, 68(6), 892-895.

Ficke, A., Gadoury, D. M., \& Seem, R. C. (2002). Ontogenic resistance and plant disease management: a case study of grape powdery mildew. Phytopathology, 92(6), 671-675.

Harms, M., Holz, B., Hoffmann, P.G., Lipps, H.P., \& Silvanus W. (2005). Occurrence of Guignardia bidwellii, the causal fungus of black rot on grapevine, in the vine growing areas of Rhineland-Palatinate, Germany. BCPC symposium proceedings, No. 81, 127-132.

Hoffman, L. E., Wilcox, W. F., Gadoury, D. M., \& Seem, R. C. (2002). Influence of grape berry age on susceptibility to Guignardia bidwellii and its incubation period length. Phytopathology, 92(10), 1068-1076.

Hoffman, L. E., Wilcox, W. F., Gadoury, D. M., Seem, R. C., \& Riegel, D. G. (2004). Integrated control of grape black rot: influence of host phenology, inoculum availability, sanitation, and spray timing. Phytopathology, 94(6), 641-650.

Kuo, K. C., \& Hoch, H. C. (1996). The parasitic relationship between Phyllosticta ampelicida and Vitis vinifera. Mycologia, 88(4), 626-634.

Lorenz, D. H., Eichhorn, K. W., Bleiholder, H., Klose, R., Meier, U., \& Weber, E. (1995). Phenological growth stages of the grapevine, Vitis vinifera L. ssp. vinifera. Codes and descriptions according to the extended $\mathrm{BBCH}$ scale. Australian Journal of Grape and Wine Research, 1(2), 100-103.

Loskill, B., Molitor, D., Koch, E., Harms, M., BerkelmannLöhnertz, B., Hoffmann, C., Kortekamp, A., Porten, M., Louis, F., \& Maixner, M. (2009). Strategien zur Regulation der Schwarzfäule (Guignardia bidwellii) im ökologischen Weinbau - Management of Black rot (Guignardia bidwellii) in organic viticulture. Final project report submitted to the German Federal Ministry of Nutrition, Agriculture and Costumer protection. Online access: http://orgprints.org/ 17072/1/17072-04OE032-jki-maixner-2009-schwarzfaeule. pdf. Accessed 04 June 2015.

Molitor, D. (2009). Biologie und Bekämpfung der Schwarzfäule (Guignardia bidwellii) an Weinreben. Dissertation, Geisenheimer Berichte Bd. 65. Gesellschaft zur Förderung der Forschungsanstalt Geisenheim, Geisenheim.

Molitor, D., \& Berkelmann-Löhnertz, B. (2011). Simulating the susceptibility of clusters to grape black rot infections 
depending on their phenological development. Crop Protection, 30(12), 1649-1654.

Molitor, D., \& Beyer, M. (2014). Epidemiology, identification and disease management of grape black rot and potentially useful metabolites of black rot pathogens for industrial applications - a review. Annals of Applied Biology, 165, 305-317.

Molitor, D., Baus, O., \& Berkelmann-Löhnertz, B. (2011). Protective and curative grape black rot control potential of pyraclostrobin and myclobutanil. Journal of Plant Diseases and Protection, 118(5), 161-167.

Molitor, D., Fruehauf, C., Baus, O., \& Berkelmann-Löhnertz, B. (2012). A cumulative degree-day-based model to calculate the duration of the incubation period of Guignardia bidwellii. Plant Disease, 96(7), 1054-1059.

Molitor, D., Caffarra, A., Sinigoj, P., Pertot, I., Hoffmann, L., \& Junk, J. (2014a). Late frost damage risk for viticulture under future climate conditions: a case study for the Luxembourgish winegrowing region. Australian Journal of Grape and Wine Research, 20(1), 160-168.

Molitor, D., Junk, J., Evers, D., Hoffmann, L., \& Beyer, M. (2014b). A high resolution cumulative degree day based model to simulate the phenological development of grapevine. American Journal of Enology and Viticulture, 65(1), $72-80$.

Nendel, C. (2010). Grapevine bud break prediction for cool winter climates. International Journal of Biometeorology, 54(3), 231-241.

Northover, P.R. (2008). Factors influencing the infection of cultivated grape (Vits spp. Section Euvitis) shoot tissue by Guignardia bidwellii (Ellis) Viala \& Ravaz. Dissertation. The Pennsylvania State University.

Rinaldi, P., Broggini, G.A.L., Gessler, C., Molitor, D., Sofia, J., \& Mugnai, L. (2013a). Guignardia bidwellii, the agent of grape black rot of grapevine, is spreading in European vineyards. 10th International Congress of Plant Pathology (ICPP 2013). Book of abstracts, 211.

Rinaldi, P., Skaventzou, M., Rossi, M., Comparini, C., Sofia, J., Molitor, D., \& Mugnai, L. (2013b). Guignardia bidwellii: Epidemiology and symptoms development in Mediterranean environment. Journal of Plant Pathology, 95(1., Supplement), S1.83-S1.84.

Rossi, V., Caffi, T., Giosuè, S., \& Bugiani, R. (2008). A mechanistic model simulating primary infections of downy mildew in grapevine. Ecological Modelling, 212, 480-491.

Rossi, V., Onesti, G., Legler, S. E., \& Caffi, T. (2014). Use of systems analysis to develop plant disease models based on literature data: grape black-rot as a case-study. European Journal of Plant Pathology, 141, 427-444.

Schultz, H. R. (1992). An empirical model for the simulation of leaf appearance and leaf-area development of primary shoots of several grapevine (Vitis vinifera L) canopy-systems. Scientia Horticulturae, 52(3), 179-200.

Smith, D. L., \& Sutherland, A. (2010). The new agweather black rot advisor and how to use it. Le Vigneron, 5(3), 5-7.

Spotts, R. A. (1977). Effect of leaf wetness duration and temperature on infectivity of Guignardia bidwellii on grape leaves. Phytopathology, 67(11), 1378-1381.

Spotts, R. A. (1980). Infection of grape by Guignardia bidwellii factors affecting lesion development, conidial dispersal, and conidial populations on leaves. Phytopathology, 70(3), 252255.

Trudgill, D. L., Honek, A., Li, D., \& Van Straalen, N. M. (2005). Thermal time - concepts and utility. Annals of Applied Biology, 146, 1-14.

Viala, P., \& Ravaz, L. (1886). Mémoire sur une nouvelle maladie de la vigne, le Black Rot (pourriture noir). Annales de l'École National d'Agriculture de Montpellier, 2, 17-58. 